(C) Volchenko D.V., Akhtyamov I.F., Terskov A.Yu., Sozonov O.A., Velichko M.N., Udalov Yu.D., Semenov M.S., Shpiz Ye.Ya., Lepsveridze L.T., 2021

DOI 10.18019/1028-4427-2021-27-1-38-42

\title{
Short-term results of total hip arthroplasty in patients with ankylosing spondylitis (preliminary report)
}

\author{
D.V. Volchenko ${ }^{1}$, I.F. Akhtiamov ${ }^{2}$, A.Yu. Terskov ${ }^{1}$, O.A. Sozonov ${ }^{1}$, M.N. Velichko ${ }^{1}$, Yu.D. Udalov ${ }^{1}$, \\ M.S. Semenov ${ }^{1}$, Ye.Ya. Shpiz ${ }^{1}$, L.T. Lepsveridze ${ }^{1}$
}

${ }^{1}$ State Research Center - Burnasyan Federal Medical Biophysical Center of Federal Medical Biological Agency, Moscow, Russian Federation ${ }^{2}$ Kazan State Medical University, Kazan, Russian Federation

\begin{abstract}
Introduction The systemic nature of the disease and the use of modern conservative therapy may cast doubt on the effectiveness and necessity of total hip arthroplasty (THA) in ankylosing spondylitis (AS). A comprehensive assessment of the functional state, quality of life (QOL) and subjective assessment of patients allows the most complete analysis of treatment results. Objective Comprehensive analysis of short-term results of quality of life, clinical and functional status and treatment satisfaction in patients with AS after THA. Materials and methods 17 patients with AS underwent primary THA ( 5 women, 12 men, average age $43.8 \pm 3.1$; from 33 to 52 years). Cases of complete bone ankylosis of the hip joint were excluded. An analysis of the functional state using Harris Hip Score and QOL (SF-36v2) was performed before surgery, 2 months, 6 months and 12 months after surgery. Patient treatment satisfaction analysis (VAS) was performed at the same follow-ups. Results A significant improvement in clinical and functional status (HHS) and QOL (SF-36v2) was obtained after 2, 6, 12 months compared with the preoperative level $(\mathrm{p}<0.05)$. High levels of patient satisfaction with treatment outcomes were achieved. Para-articular ossification ( 3 patients, $18 \%$ ), a hematoma in the postoperative wound area (1 patient, $6 \%)$, implant dislocation (1 patient, $6 \%$ ) were the main complications. Conclusion THA in patients with AS improves not only the functional state but also the QOL compared with the preoperative level.
\end{abstract}

Keywords: ankylosing spondylitis, total hip arthroplasty, quality of life

\section{INTRODUCTION}

Ankylosing spondylitis (AS) (ICD code M46.8) is a chronic inflammatory systemic disease involving the spine, sacroiliac joints, cardiovascular system, peripheral joints and enthesitis in the pathological process [1].

According to the New York Criteria (1984), the pathognomonic clinical manifestations of AS include prolonged, more than 3 months, pain in the lumbar spine, limitation of movement in the lumbar spine, and restriction of chest excursion. A specific radiological symptom is unilateral or bilateral sacroiliitis. The diagnosis of AS is established with at least one clinical and one radiological signs [2]. AS is mostly diagnosed at the age of 30-40 years; males are affected 2-3 times more often than females. Laboratory tests reveal the genetic marker HLA-B27 in approximately $90 \%$ of patients.

The inflammatory processes developing in AS frequently lead to progressive destruction of the joints of the lower extremities, with a tendency to ankylosis
[3]. Patients with significant functional limitations, severe pain and impairment in their quality of life (QoL) are candidates for surgical treatment such as total hip arthroplasty (THA). However, the frequency of complications after arthroplasty is significantly higher in severe contracture or ankylosis of the joint than in primary osteoarthritis [4].

The systemic nature of the disease and the use of conservative therapy in a number of cases may call into question the effectiveness and necessity of THA in AS. To conduct a full analysis of THA results, it is necessary to assess the clinical and functional state in combination with its subjective perception by patients $[5,6]$. In order to obtain additional data, QoL is studied to reveal the effect of the disease and of the surgical intervention on all components of health, physical, psychological and social functioning [7].

Purpose Comprehensive analysis of short-term results of quality of life, clinical and functional status and treatment satisfaction in patients with AS after THA.

\section{MATERIAL AND METHODS}

The study included 17 patients with AS (5 women, 12 men) in the mean age $43.8 \pm 3.1$ (range, 33 to 52

years) who underwent primary total arthroplasty (14 cementless, 3 cemented) for joint destruction.

Dal Volchenko D.V., Akhtyamov I.F., Terskov A.Yu., Sozonov O.A., Velichko M.N., Udalov Yu.D., Semenov M.S., Shpiz Ye.Ya., Lepsveridze L.T. Short-term results of total hip arthroplasty in patients with ankylosing spondylitis (preliminary report). Genij Ortopedii, 2021, vol. 27, no 1, pp. 38-42. DOI 10.18019/1028-4427-2021-27-1-38-42 
Complete bone ankylosis of the hip joint was not diagnosed in any of the cases.

Preoperative examination of patients included collection of complaints, medical history, measurements of limb length, range of motion in the joints, pelvic $\mathrm{X}$-ray and conventional laboratory tests. Before the operation, the patients were consulted by a therapist, anesthesiologist, rheumatologist, neurosurgeon and other specialists according to indications. All patients underwent assessment of QoL and functional state according to Harris prior to surgery.

To most accurately restore the normal biomechanical relationships in the hip joint, preoperative planning was based on X-ray study of the pelvic bones in the frontal view, and, if necessary, using magnetic resonance imaging and computed tomography.

THA was performed in the supine position from the anterolateral approach according to Hardinge.

In most cases, cementless components were used. In cement-based implant, the stem was installed after retrograde cement injection using a syringe. To create a uniform mantle, a bone plug or a polyethylene restrictor was inserted into the medullary canal distal to the end of the femoral component.

In the postoperative period, all patients underwent prophylaxis of venous thromboembolic complications (early activation, anticoagulants and elastic compression of the lower extremities for 6 weeks). For the prevention of infectious complications, cefazolin $1.0 \mathrm{i} / \mathrm{v}$ was used 30 minutes before the incision, then $1.0 \mathrm{i} / \mathrm{v}$ twice a day in the first day after the operation.

From the second day, exercise and physical therapies were prescribed, walking with additional support means with a dosed load on the operated limb was allowed up to 8 weeks from the moment of surgery.

The THA results were assessed 2 months, 6 months, 12 months after the operation and included the analysis of X-rays and functional studies, QoL, complications and patient satisfaction with treatment.

The Harris Hip Score (HHS) questionnaire was used to assess the functional state of the hip joint [8]. This questionnaire consists of 18 questions, the answers to which correspond to a certain number of points, the result is assessed according to the total score: $90-100$ points correspond to excellent, 8089 points to good, $70-79$ points to fair, and less than 70 points to poor result.

The QoL of patients was assessed using the SF$36 \mathrm{v} 2$ questionnaire, which was completed directly by the patient, and if necessary with the participation of medical personnel. The test consists of 36 questions regarding physical and mental health. The results are grouped into eight scales: physical functioning, daily activity, pain, general health, life activity, social functioning, emotional state, and mental health. The results are presented as scores; higher scores correspond to a higher level of QoL. Assessment by scales is grouped into two sectionss, physical component of health and psychological component of health [9].

For the patients' subjective assessment of the results of surgical treatment, a visual analogue scale (VAS) was used (minimum 0 points, maximum 10 points). Patients gave a certain number of points for the treatment. The number of points $0-3$ corresponded to low satisfaction with the treatment, 4-7 points average, $8-10$ points - high.

\section{Radiographic evaluation}

To control the results of THA, X-rays of the pelvis in frontal view and X-ray of the operated joint in axial views were taken. The radiographs were analyzed for the development of early instability.

To assess the degree of development of paraarticular ossification, we used the Brooker A.F. et al. classification (1973) [10], according to which there are four classes (Fig. 1):
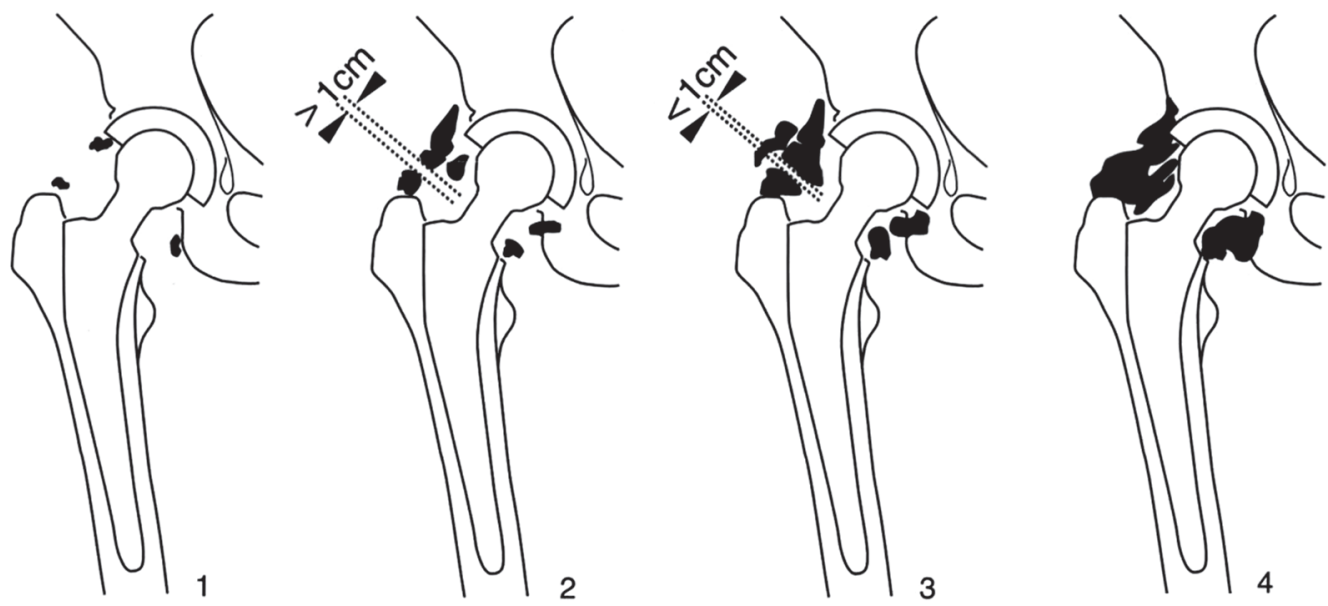

Fig. 1 Classification of para-articular ossification according to Brooker A.F. et al. (1973) 
Class I - isolated bone formation in the joint soft tissues;

Class II - bone outgrowth in the pelvic and femoral areas that are oriented to each other and the distance between them is more than $1 \mathrm{~cm}$;

Class III - distance between bony outgrowths is less than $1 \mathrm{~cm}$;

Class IV - complete ankyloses of the joint and there are no movements in it.

In some cases, radiographic grade 4 (ankylosis) can be mistakenly diagnosed when multiple ossification features layers on top of each other. In this case, it is recommended to perform functional radiographs in two projections with an analysis of the range of motion in the hip joint.

In addition, the complication rate and revision interventions were analyzed in the study group.

IBM SPSS Statistics v.23 was used for statistical analysis of the obtained data, arithmetic mean values and mean error were calculated. To assess the differences between the results, Student's t-test was applied. Differences were considered significant at a significance level of $\mathrm{p}<0.05$.

\section{RESULTS}

The results of surgical treatment were studied in 17 patients ( 5 women, 12 men) 2 months, 6 months and 12 months after the operation.

The main types of complications recorded during the follow-up period are shown in Table 1.

Table 1

Complication in the postoperative period

\begin{tabular}{|l|c|}
\hline \multicolumn{1}{|c|}{ Type of complication } & $\mathrm{n}=17$ \\
\hline Hematomas, $\mathrm{n}(\%)$ & $1(6)$ \\
\hline Para-articular ossification, $\mathrm{n}(\%)$ & $3(18)$ \\
\hline Implant dislocation, $\mathrm{n}(\%)$ & $1(6)$ \\
\hline
\end{tabular}

One patient $(6 \%)$ developed a hematoma in the area of surgery, which required a second operation. Evacuation and revision of the postoperative wound were performed under intravenous anesthesia.

Microbiological inoculation of the discharge did not reveal any growth. The postoperative wound healed by primary intention.

\section{Functional and QoL assessment}

The analysis of clinical and functional results with HHS found a significant positive dynamics in the state of patients in the postoperative period at each of the follow-up time-points $(\mathrm{p}<0.05)$.

Higher results of the SF-36v2 questionnaire were obtained in the psychological component $(p<0.05)$. The physical component of SF-36v2 also showed positive dynamics compared to preoperative indicators $(p<0.05)$.

The results of a subjective assessment of the outcomes of surgical treatment and a comprehensive assessment are presented in Table 2.

Table 2

Dynamics of evaluation according to HHS, SF-36v2, VAS

\begin{tabular}{|l|c|c|c|c|c|c|c|}
\hline \multicolumn{1}{|c|}{ Parameter } & $\begin{array}{c}\text { Before } \\
\text { THA }\end{array}$ & $\begin{array}{c}2 \text { months } \\
\text { after THA }\end{array}$ & $\begin{array}{c}\text { 6 months } \\
\text { after THA }\end{array}$ & $\begin{array}{c}12 \text { months } \\
\text { after THA }\end{array}$ & $\mathrm{t}_{1}$ & $\mathrm{t}_{2}$ & $\mathrm{t}_{3}$ \\
\hline HHS & $37.3 \pm 5.2$ & $75.2 \pm 4.2$ & $79.4 \pm 5.3$ & $79.9 \pm 4.1$ & $5.67^{*}$ & $5.67^{*}$ & $6.43^{*}$ \\
\hline SF-36v2, physical component & $34.8 \pm 5.1$ & $48.7 \pm 3.7$ & $54.3 \pm 4.2$ & $55.1 \pm 3.8$ & $2.21^{*}$ & $2.95^{*}$ & $3.19^{*}$ \\
\hline SF-36v2, psychological component & $40.2 \pm 5.7$ & $67.5 \pm 3.8$ & $70.5 \pm 3.2$ & $72.1 \pm 5.3$ & $3.99 *$ & $4.64^{*}$ & $4.1 *$ \\
\hline Satisfaction with treatment (VAS) & - & $7.7 \pm 1.5$ & $8.1 \pm 1.2$ & $8.2 \pm 1.3$ & & & \\
\hline
\end{tabular}

$*-\mathrm{p}<0.05 ; \mathrm{t}_{1}-$ Student's test when comparing the results before surgery / after 2 months; $\mathrm{t}_{2}-$ Student's criterion when comparing results before surgery / after 6 months; $t_{3}$-Student's test when comparing results before surgery / after 12 months.

\section{DISCUSSION}

Ankylosing spondyloarthritis belongs to the group of seronegative spondyloarthritis and is a systemic inflammatory disease. The incidence of the disease among the general population is about $1 \%$.

The complexity of treatment of patients with AS is associated with the systemic nature of the disease, the involvement of tendons and the spine in the pathological process. Moreover, peripheral arthritis of the joints of the lower extremities occurs in more than half of the patients. The hip joints in AS are affected in $30-50 \%$, and the process is bilateral in $47-90 \%$ of revealed cases [11]. Due to severe pain, arthritis leads to significant functional impairments, decreased QoL, social maladjustment and, often, patient disability.

The prognosis of hip joint ankylosis is unfavorable. Surgical treatment in this case is associated with a high frequency of complications (dislocations, infectious, etc.) and in some cases requires the use of special designs [12]. In our study, there were no patients with ankylosis of the hip joint.

As reported, AS may be a predisposing factor for the developmentofpara-articularossification after THA [13]. To prevent this type of complication, it is recommended 
to adhere to atraumatic surgical techniques, perform thorough hemostasis, remove nonviable tissues and all bone fragments; in the postoperative period the use of nonselective non-steroidal anti-inflammatory drugs (indomethacin, ibuprofen, etc.) and radiotherapy. Three patients $(18 \%)$ from our study had ossification of the second class according to the Brooker F.A. classification, but in none of those cases required additional surgical interventions.

One patient $(6 \%)$ developed dislocation of the implant in the postoperative period, and closed reduction was performed. After the course of exercise therapy and adherence to the recommendations, repeated dislocations were not recorded.

There were no cases of deep wound infection and thromboembolic complications in the followup period. Also, no aseptic instability of the implant components was revealed. At the same time, it should be noted that for an objective assessment of the "survival" of implants, it is necessary to control the condition in the long term.
The systemic AS nature has a significant impact on the dynamics of clinical and functional results after surgical treatment. Enthesitis in AS, destruction of articular surfaces, peripheral arthritis, spinal lesions lead to a significant decrease in the rehabilitation potential. It may be one of the main reasons for a slow recovery of the clinical and functional status. In our opinion, lower scores in the physical component of SF-36v2 compared to the psychological component of SF-36v2 are related to the fact. At the same time, we revealed a significant improvement in the results on the HHS and SF-36v2 scores $(\mathrm{p}<0.05)$ in each of the follow-up periods compared with the preoperative level. In addition, subjective assessment corresponded to the high patient satisfaction with the performed surgical treatment.

It should be noted that the analysis of the results in our study was conducted for a short postoperative period of time in a small number of patients. Nevertheless, THA in patients with AS improves the functional state and QoL in the short term.

\section{CONCLUSION}

THA is one of the most effective orthopedic interventions. The results of our study showed that THA in patients with AS may improve not only the functional state but also the QoL in comparison with the preoperative level. However, the rehabilitation potential in this disorder is significantly restricted by the systemic nature of the disease, concomitant enthesitis, damage to adjacent joints and the spine. To improve the results of surgical treatment, close cooperation of orthopedists, rheumatologists, neurosurgeons and rehabilitation specialists is required.

The study was not sponsored. The authors declare no obvious and potential conflicts of interest related to the publication of this article.

\section{REFERENCES}

1. Erdes Sh.F., Badokin V.V., Bochkova A.G., Bugrova O.V., Gaidukova I.Z., Godzenko A.A., Dubikov A.A., Dubinina T.V., Ivanova O.N., Korotaeva T.V., Lapshina S.A., Nesmeianova O.B., Nikishina I.P., Otteva E.N., Raskina T.A., Rebrov A.P., Rumiantseva O.A., Sitalo A.V., Smirnov A.V. O terminologii spondiloartritov [On the terminology of spondyloarthritis]. Nauchno-Prakticheskaia Revmatologiia, 2015, vol. 53, no. 6, pp. 657-660. (in Russian) DOI: 10.14412/1995-4484-2015-657-660

2. Erdes Sh.F. Istoriia ankiloziruiushchego spondilita: put ot dinozavrov do ASAS [History of ankylosing spondylitis: the way from dinosaurs to ASAS]. Nauchno-Prakticheskaia Revmatologiia, 2014, vol. 52, no. 1, pp. 110-114. (in Russian). DOI: 10.14412/1995-4484-2014-110-114

3. Vander Cruyssen B., Muñoz-Gomariz E., Font P., Mulero J., de Vlam K., Boonen A., Vazquez-Mellado J., Flores D., Vastesaeger N., Collantes E.; ASPECT-REGISPONSER-RESPONDIA working group. Hip involvement in ankylosing spondylitis: epidemiology and risk factors associated with hip replacement surgery. Rheumatology (Oxford), 2010, vol. 49, no. 1, pp. 73-81. DOI: 10.1093/rheumatology/kep174

4. Tikhilov R.M., Shubniakov I.I., Miasoedov A.A., Pliev D.G., Karelkin V.V., Berezin G.V. Endoprotezirovaniia tazobedrennogo sustava pri kostnykh ankilozakh razlichnoi etiologii, prichiny i rezultaty [Procedures of the hip arthroplasty for bone ankyloses of different aetiology, causes and results]. Sovremennye Problemy Nauki i Obrazovaniia, 2018, no. 2, pp. 1-10. (in Russian)

5. Akhtyamov I.F., Guryleva M.E., Iuosef A.I., Kovalenko A.N., Garifullov G.G., Turenkov S.V. Otsenka kachestva zhizni s patologiei tazobedrennogo sustava [Evaluation of the quality of life with the hip pathology]. Vestnik Travmatologii i Ortopedii im. N.N. Priorova, 2007, no. 1, pp. 37-42. (in Russian)

6. Volchenko D.V., Kim N.I. Otsenka kachestva zhizni patsientov s travmami i zabolevaniiami tazobedrennogo sustava [Evaluation of the quality of life in patients with injuries and diseases of the hip]. Vestnik Rossiiskogo Gosudarstvennogo Meditsinskogo Universiteta, 2005, no. 3, pp. 54-55. (in Russian)

7. Novik A.A., Ionova T.A. Rukovodstvo po issledovaniiu kachestva zhizni v meditsine [Guidelines for Research on Quality of Life in Medicine]. $2^{\text {nd }}$ Ed. Shevchenko Iu.L., editor. M., Olma Media Grupp, 2007, 313 p. (Medicine of the XXI Century). (in Russian)

8. Harris W.H. Traumatic arthritis of the hip after dislocation and acetabular fractures: treatment by mold arthroplasty. An end-result study using a new method of result evaluation. J. Bone Jt. Surg., 1969, vol. 51, no. 4, pp. 737-755.

9. Ware J., Kosinski M., Bjorner J., Turner-Bowker D., Gandek B., Maruish M.. User's manual for the SF-36v2 ${ }^{\circledR}$ Health Survey. $2^{\text {nd }}$ ed. Lincoln (RI), QualityMetric Incorporated, 2007, 309 p.

10. Brooker A.F., Bowerman J.W., Robinson R.A., Riley L.H. Jr. Ectopic ossification following total hip replacement. Incidence and a method of classification. J. Bone Joint Surg. Am., 1973, vol. 55, no. 8, pp. 1629-1632.

11. Guan M., Wang J., Zhao L., Xiao J., Li Z., Shi Z. Management of hip involvement in ankylosing spondylitis. Clin. Rheumatol., 2013, vol. 32, no. 8, pp. 1115-1120. DOI: 10.1007/s10067-013-2278-3 
Genij Ortopedii, Vol. 27, no 1, 2021

12. Gautam D., Malhotra R. Total Hip Arthroplasty in Ankylosing Spondylitis with Extension Contracture of Hips. J. Arthroplasty, 2019, vol. 34, no. 1, pp. 71-76. DOI: 10.1016/j.arth.2018.08.025

13. Board T.N., Karva A., Board R.E., Gambhir A.K., Porter M.L. The prophylaxis and treatment of heterotopic ossification following lower limb arthroplasty. J. Bone Jt. Surg. Br., 2007, vol. 89, no. 4, pp. 434-440. DOI:10.1302/0301-620x.89b4.18845

Received: 17.04 .2020

\section{Information about the authors:}

1. Denis V. Volchenko, M.D., Ph.D.,

Burnasyan Federal Medical Biophysical Center of Federal Medical Biological Agency, Moscow, Russian Federation, Email: den4099@yandex.ru

2. Ildar F. Akhtyamov, MD, Ph.D., Professor,

Kazan State Medical University, Kazan, Russian Federation,

Email: yalta60@mail.ru

3. Aleksandr Yu. Terskov, M.D., Ph.D.,

Burnasyan Federal Medical Biophysical Center of Federal Medical Biological Agency, Moscow, Russian Federation, Email: terskov72@mail.ru

4. Oleg A. Sozonov, M.D.,

Burnasyan Federal Medical Biophysical Center of Federal Medical Biological Agency, Moscow, Russian Federation, Email: brachio@gmail.com

5. Maksim N. Velichko, M.D.

Burnasyan Federal Medical Biophysical Center of Federal Medical Biological Agency, Moscow, Russian Federation, Email: maxveldoc@yandex.ru

6. Yuri D. Udalov, M.D., Ph.D.,

Burnasyan Federal Medical Biophysical Center of Federal Medical Biological Agency, Moscow, Russian Federation, Email: udalov@fmbcfmba.ru

7. Maksim S. Semenov, M.D., Ph.D.,

Burnasyan Federal Medical Biophysical Center of Federal Medical Biological Agency, Moscow, Russian Federation, Email: semenov@fmbcfmba.ru

8. Yevgeny Ya. Shpiz, M.D.,

Burnasyan Federal Medical Biophysical Center of Federal Medical Biological Agency, Moscow, Russian Federation, Email:shpiz@inbox.ru

9. Levan T. Lepsveridze, M.D., Ph.D.,

Burnasyan Federal Medical Biophysical Center of Federal Medical Biological Agency, Moscow, Russian Federation, Email: lepsveridze@fmbcfmba.ru 